\title{
Analysis of incompatibility barriers during cross-pollinations among Phaseolus L. and other leguminous plants
}

\author{
Pamphile NGUEMA NDOUTOUMOU ${ }^{1 *}$, Marie MALICE ${ }^{2}$, André TOUSSAINT $^{2}$ and \\ Jean Pierre BAUDOIN ${ }^{2}$
}

\author{
${ }^{1}$ Université des Sciences et Techniques de Masuku, Institut National Supérieur d'Agronomie et de \\ Biotechnologies (INSAB), B.P. 99 Poto-Poto Franceville, Gabon. \\ ${ }^{2}$ Université de Liège, Gembloux Agro Bio-Tech, Unité de Phytotechnie Tropicale et Horticulture, \\ Passage des Déportés, 2. B-5030, Gembloux, Belgique. \\ ${ }^{*}$ Corresponding author; E-mail: pamphilen@hotmail.com; Tel : +24107 770705
}

\begin{abstract}
Plant breeding is intended to seek for ways of realizing a genetic structure adapted to criteria and population needs. In this context, cross-pollinations are for great interest. They offer the means of creating a wide genotypic variability. However, a limited number of species are able to undergo hybridization studies. In Phaseolus L., improvement can be envisioned by either exploiting the primary genetic pool of the species, or the genetic variability of other species. In fact, there are wild or wild-like species more resistant to stresses or diseases than the cultivated ones. The methods of embryo rescues facilitate the interspecific crosses and contribute to exploiting the available genetic diversity within plant germplasm. Difficulties related to obtaining hybrids in grain legumes, and Phaseolus L. in particular, are reported in this research. It is possible to avoid the incompatibility barriers based on their appearance time. When they are pre-zygotic, the use of growth regulators during pollination is recommended. The in vitro explants culture is the most usual method to overcome the post-zygotic barriers. The mechanisms leading to abortion of hybrid embryos, as well as adequate methods to overcome the interspecific incompatibilities should be subjected to further studies.

(c) 2013 International Formulae Group. All rights reserved.
\end{abstract}

Keywords: Abortion, hybridization, interspecific barriers, Phaseolus L., plant embryos.

\section{INTRODUCTION}

In plant kingdom, it is possible to increase the variability within the germplasm of the genetic pool using interspecific or intergenic hybridizations. This constitutes an interesting way for introgression of advantageous characters in cultivars with appreciated economic values (Nyabyenda, 2005; Nzungize, 2012). According to AlAhmad et al. (2006), Hillocks et al. (2006) and Nzungize et al. (2011), it is usually the case in interspecific hybridization between Phaseolus vulgaris L. and others species like Phaseolus coccineus L. or Phaseolus polyanthus Greenman.

In fact, the common bean $(P$. vulgaris L.) is the most important food legume grown worldwide (Broughton et al., 2003; Nzungize, 2012). It is a main crop in many countries of Sub-Saharan Africa, it is grown mainly by small farmers and constitutes a principal 
source of vegetable proteins for populations. But, important yield loss of common bean is partly due to biotic and abiotic stresses (Mahuku et al., 2003). So, it is important to consider its improvement through hybridizations within the genus Phaseolus L.

This problematic concerns a lot of other plants and solutions differ from one specie to another, but the resort to biotechnology tool cannot be avoided.

However, the hybrids are not always easily obtained as the result of crosses. Several plant genus and species show incompatibilities during hybridizations (Hillocks et al., 2006; Barikissou, 2012). The technics requested to go round the natural barriers of fertility differ depending on their survival time according to Jansky (2006) and Tsiantis and Hay (2003).

In this manuscript, several cases of pre-zygotic and post-zygotic incompatibility barriers occurring during many plant crosses are identified and described. Then, some techniques which can be used to overcome these interspecific barriers are suggested according to plant biotechnology recent advances.

\section{MANIFESTATIONS OF INTERSPECIFIC INCOMPATIBILITY BARRIERS}

The incompatibilities occurring during the pollination process are referred to as prezygotic, and can be illustrated by the absence of pollen germination on the stigma (Kouadio et al., 2006), the lack of pollen tube growth on the style tissues (Guéritaine et al., 2003; Jansky, 2006; Kaufmane and Rumpunen, 2002), the incapacity of the pollen tube to penetrate the ovule (Fratini et al., 2006), or the lack of the parental gametes fusion (Gurusamy et al. 2006).

When the pollination is completed and the incompatibility occurs during or after the syngamy, the barriers are named post-zygotic (Gurusamy, et al., 2007; Nguema et al., 2013), and often lead to interruption of the embryogenesis process, with different origin causes.

The action of genes can instigate the interruption of the development of the endosperm or its degeneration shortly after fertilization (Silué, 2009), thus preventing the pro-embryo from nutritional needs necessary for growth (Jenczewski et al., 2003; Jansky, 2006). Failure of the development of suspensor is responsible for the interruption of embryo growth before that of endosperm, leading to embryo abortion (Tischner et al., 2003) in most plant genus, whatever the development stage of the embryo (Jansky, 2006; Kouadio et al., 2006). When the hybrid grains are obtained, other difficulties can occur within the hybrid populations, notably the sterility of $F_{1}$ and $F_{2}$ hybrids, the unbalance between the future generations, the transmission of desired characters and/or the return of offsprings to one of the parental forms in the most advanced generations.

\section{INCOMPATIBILITIES WITHIN THE GENUS PHASEOLUS}

Within the genus Phaseolus, the particular stage to which lead the development of hybrid embryos depends on the maternal parent, the biological form of the parental genotypes and the ability of crosses (Tsiantis and Hay, 2003; Umehara et al., 2007).

The utilization of $P$. vulgaris cytoplasm easily conducts to hybrid plants, whatever the biological form of parents. Hybrid embryos present a normal or fast development in some cases than that of the parental embryos species. The hybrids however, demonstrate a progressive loss of pollinator characters in further generations. In contrast, when Phaseolus coccineus (or Phaseolus polyanthus) ( $($ ) is crossed with Phaseolus vulgaris, abortion of hybrid embryos is frequent from the pre-globular to the cotyledonal stage (Geerts et al., 2002; Nguema et al., 2009). The most probable cause of these abortions is attributed to the late development of endosperm compared to the embryo. This may be due to insufficient nutritional needs and the incoherence of the histological development between embryo and pod structures (Nguema et al., 2013). At the globular stage, the blockage can be attributed to development problems of endosperm or nutrition of the ovule. The same processes can 
occur at the end of the globular stage (Barikissou, 2012). The hormonal metabolism also widely influences the development of the interspecific embryos (Geets et al., 2002). Despite the post-zygotic barriers, when Phaseolus coccineus or Phaseolus polyanthus $(P)$ is crossed with Phaseolus vulgaris, there are good possibilities of expression and introgression of characters compared to reciprocal crosses (Wolf et al., 2001; Chen et al., 2002).

The early rescue of hybrid embryos via in vitro tissues culture appears important for overcoming the limiting barriers for obtaining the hybrids within the genus Phaseolus (Barikissou, 2012). The technique developed and improved by several authors for in vitro culture of Phaseolus hybrid embryos is summarized in three steps as follows: (i) the extraction and transfer of embryos on in vitro culture medium; (ii) the stimulation of embryos growth on the first medium; (iii) the rooting followed by development of embryo on a second medium (Umehara et al., 2007). The in vitro culture was improved (Geerts et al., 2002) for the rescue of heart-shaped embryos of Phaseolus polyanthus and Phaseolus vulgaris. It allows a significant increase of the germination rate (averagely 20\%) of embryos that well develop on different culture media to give rise to an elevated number of normal plantlets. The success is limited to heart-shaped embryos of 8 days old. The development of embryos in Phaseolus vulgaris depends partly on the osmotic gradient between young developing seeds and pods (Geerts et al., 2002). The growth of pods seems to be appropriate for the rescue of immature embryos and the survival of hybrid plantlets of the genus Phaseolus when embryos abort at very early stage (Nguema et al., 2009). There are difficulties during extraction of embryos from ovule due to their relatively small size and fragility.

\section{THE CASE OF OTHER LEGUMINOUS PLANTS}

During crosses between Vigna unguiculata L. Walpers and V. vexillata (L.) A. Rich., incompatibilities occur between pollen and stigma on one hand, and between pollen and style on the other hand (Kouadio et al., 2006) the case is similar during hybridizations within potato group (Jansky, 2006). Opposite to the previous observations, it was possible for the first time to regenerate plant hybrids through interspecific combination using in vitro culture of immature embryos (Gupta et al., 2002; Hillocks et al., 2006). There are also incompatibilities between $V$. radiata $\mathrm{L}$. Wilczek (P) and $V$. mungo L. Hepper (Kouadio et al., 2006). The seeds produced are not well developed and grown into plants with low yielding capacity. In contrast, in reverse crosses, seeds are totally or partially empty and fail to grow. During these crosses the percentage of embryos is very high (Gupta et al., 2002; Kouadio et al., 2006). The use of $V$. mungo as a recurrent parent for successive crosses, limits these massive abortions, but generates short parental forms. Table 1 reports on the interspecific crosses cases realized in grain legumes and other plant groups.

This table describes the incompatibilities and methods of obtaining the hybrid plants. These incompatibilities are generally revealed by the abortion of embryos during their early stage of development. The embryo rescue techniques by in vitro culture are used to go round these post-zygotic incompatibilities.

\section{POSSIBILITIES OF OVERCOMING OF INCOMPATIBILITIES BARRIERS}

In interspecific hybridization, precautions are taken to insure the success of crossing. The first consist of choosing the parents according to the genetic distance in order to increase the chances of obtaining hybrids. The application of growth regulators to pistils for delaying the initiation of abscission of pods is usual for numerous interspecific hybridizations. This method was successfully used for Cicer arietinum L. and C. pinnatifidum L. Hybrid plants derived from Vigna mungo (black gram) and Vigna radiata (green gram) were favoured by the treatment of pistil with gibberellic acid (GA3), 
(Kaufmane and Rumpunen, 2002) up to 48 hours after pollination (Gupta et al., 2002).

The technique of somatic duplication of chromosomes (mitotic polyploidization) allows the production of fertile diploid hybrids (Baudoin et al., 2004; Silué, 2009). It is important for the evolution of higher plants. In fact, regular meiosis of allopolyploids species (i.e. those that contain a complete set of chromosomes from at least two distinct but related parents) implies that the pairing or recombination between homologous chromosomes from each parent should precisely be controlled to avoid bad segregation of chromosomes (Jenczewki et al., 2003).

When the interspecific crosses are not easily successful and the incompatibility barriers are essentially post-zygotic, embryo rescue by in vitro culture become a logic step according to many authors as Fratini et al. (2006) and Gurusamy et al. (2007). In general, embryos are extracted from ovules in pods. In certain cases, it's not easy. The embryo rescue at this time is possible through the prior culture of a part of entire ovule or pod (Barikissou, 2012). It is also the case of Brassica spp., Cucumis spp., Gossypium spp., Helianthus L. and Nicotiana L. according to (Chen et al., 2002) and (Al-Ahmad et al., 2006). The growth of part of the pod in the culture medium and in the presence of anther is required for the rescue of immature embryos in the genus Lillium L. This allows the embryo to benefit from the artificial conditions of the medium without a straight separation from the mother link (Umehara et al., 2007). Embryo rescue gives rise to intergenic and interspecific hybrids (Yamagishi et al., 2002). It is usually used when the endosperm degenerate rapidly to avoid the death of embryos. In this case, the properties of the endosperm should be taken into consideration (its composition, its kinetic of development, its ability to synthesize nutrients and make them available to embryo). For a direct rescue of the embryo, it should be excised and transferred on a nutritious medium.
Generally, the method has evolved by the establishment of more efficient media adapted for the specific needs of embryos, while taking into consideration their development stages and the crossed species. The indirect rescue of embryos implies subsequent stages in vitro. Thus, the cultures of pod (Geerts et al., 2002), ovule, epillets and the callogenesis of a small embryo followed by its regeneration (Nzungize, 2012), are the indirect methods requiring more time, but sometimes compulsory. Results differ from one genus to another and from one interspecific cross to another. The in vitro culture can allow the survival of zygote hybrids up to the adult stage in the case of failure linked to the development of zygote within the mother structure (e.g. late initiation of endosperm or in the embryo divisions). Therefore, the rescue of embryos is important for crossings in order to obtain plants from immature embryos while reducing the culture cycle (Gupta et al., 2002; Jansky, 2006). This technique is used as a tool of immature embryo rescue able to evolve in the environment where the endosperm could be fainted. Considering the small size of the embryo, it is vital to optimize the components of culture medium. Many cases of the rescue of embryos through the in vitro culture exist in the plant kingdom (Table 1). The development of in vitro culture can be extended to several types of explants. The culture of embryogenic callus also constitutes an efficient mean of going round the postzygotic incompatibility barriers when they are very strong. Protoplast fusion can lastly contribute to enlarge the potentialities of interspecific hybridization and offer the new perspectives. These products so called "cybrids" correspond to interspecific or intergenic hybrid cytoplasms (Yamagishi et al., 2002).

In the same way, Damier and Tagu (2003) in the one hand recommend on the use of molecular hybridization, while Jenczewski et al. (2003) in the other hand suggest the introgression of characters by the transgene methods. 
Table 1: Interspecific crosses in leguminous and others plants.

\begin{tabular}{|c|c|c|}
\hline Genus & Crosses & References \\
\hline Cicer & Wild forms $\mathrm{x}$ cultivars & Singh et al., 2008 \\
\hline Arachis & Arachis hypogea L. (cv) x A. villosa Benth. (wf) & Banerjee et al., 2007 \\
\hline Cajanus & $\begin{array}{l}\text { Cajanus spp (sv) x C. cajanus Millsp. } \\
\text { C. cajan Millsp. x C. reticulates F. Muell. }\end{array}$ & Chen et al., 2002 \\
\hline Vigna & $\begin{array}{l}\text { V. unguiculata L. Walp. x V. vexillata L. A. } \\
\text { Rich. } \\
\text { V. luteola Benth. x V. marina Merrill. }\end{array}$ & $\begin{array}{c}\text { Chen et al., 2002, Gupta et } \\
\text { al.,2002; Kouadio et al., } 2006\end{array}$ \\
\hline Eucalyptus L. & E. macrocarpa Hook. x E. youngiana F. Muell. & Guéritaine et al., 2003 \\
\hline Helianthus L. & H. giganteus Louleiro x H. annuus L. & Jansky, 2006 \\
\hline Cuphea $\mathrm{L}$. & $\begin{array}{l}\text { C. paucipetala S. A. Graham x C. laminuligera } \\
\text { Koeh. }\end{array}$ & Evangelista and Cermak, 2007 \\
\hline Oryza L. & O. sativa L. x O. minuta J. S. Presl. & Wolf et al., 2001 \\
\hline Fagopyrum Hill. & $\begin{array}{l}\text { F. esculentum Moench x F. zuogongense Q. F. } \\
\text { Chen }\end{array}$ & Wang et al., 2002 \\
\hline Cucumis L. & C. sativus L. x C. hystrix Charkr & Chen et al., 2002 \\
\hline
\end{tabular}

\section{CONCLUSION}

The interspecific hybridization contributes to increase the genetic diversity in plants. It is necessary for the plant breeder to have the maximum phytogenetic resources. This will occur before hybridization and introgression of desired characters and the creation of new plant materials. The phyletic distance between species has an important influence in the success of crossing. New individual obtained with or without desired characters is not always easy due to incompatibilities encountered between the genetic pools of species or during the interspecific crosses in Phaseolus. The sens of cross is important as the choice of genotypes used. The abiotic factors and the age of plants also influence the potentialities of the reproductive organs. The incompatibility barriers can be avoided by resorting to diverse techniques according to the reproductive process (pre and post-zygotic stages). It is necessary to proceed by approach during the evidence of incompatibility. This consists of looking at the mechanisms of pollination, fecundation and embryogenesis. The use of growth regulators applied in vivo or in situ on flours after pollination is the most common used method to overcome the pre-zygotic barriers. Above this stage, a precise exam of fecundation is required for identifying the probable causes of the absence of eggs fusion. The post-zygotic events preventing the development of embryos could be analyzed. It is only at this time that it can be envisioned that the embryo rescue by in vitro culture of explants in adequate media and according to adapted protocols in each case in order to obtain viable and adult plants with desired characters according to crosses results.

\section{REFERENCES}

Al-Ahmad H, Galili S, Gressel J. 2006. Infertile interspecific hybrids between transgenically mitigated Nicotiana tabacum and Nicotiana sylvestris did not backcross to N. sylvestris. Plant Science, 170: $953-961$.

Banerjee P, Maity S, Maiti SS, Banerjee N. 2007. Influence of genotype on in vitro multiplication potential of Arachis hypogaea L. Acta Botanica Croatica, 66: 15-23.

Barikissou E. 2012. Elaboration d'un protocole in vitro de contournement des barrières d'incompatibilité génétique 
entre Phaseolus coccineus L. et $P$. vulgaris L. Thèse de doctorat. Faculté universitaire des Sciences Agronomiques. Gembloux, Belgique, 174 p.

Baudoin JP, Silué S, Geerts P, Mergeai G, Jacquemin JM, Toussaint A. 2004. Interspecific hybridization with Phaseolus vulgaris L.: Embryo development and its genetics. In Recent Research Developments in Genetics and Breeding I (Part II), Pandalai SG (ed). Research Signpost: Trivandrum, Kerala, India.

Broughton WJ, Hernandez G, Blair MW, Beebe S, Gepts P, Vanderleyden J. 2003. Beans (Phaseolus spp.) - Model Food Legumes. Plant and Soil, 252: 55-128.

Chen JF, Staub J, Adelberg J, Lewis S, Kunkle B, Chen JF. 2002. Synthesis and preliminary characterization of a new species (amphidiploid) in Cucumis. Euphytica, 123(3): 315-322.

Damier L, Tagu D. 2003. Hybridation moléculaire. In Principes des Techniques de Biologie Moléculaire. Tagu D, Moussard C (eds). INRA: Paris, France; 32-34.

Evangelista RL, Cermak SC. 2007. Full-Press Oil Extraction of Cuphea (PSR23) Seeds. J. Am. Oil. Chem. Soc., 84: 1169-1175.

Fratini R, García P, Ruiz ML. 2006. Pollen and pistil morphology, in vitro pollen grain germination and crossing success of Lens cultivars and species. Plant Breeding, 125: 501-505.

Geerts P, Toussaint A, Mergeai G, Baudoin JP. 2002. Study of the early abortion in reciprocal crosses between Phaseolus vulgaris L. and Phaseolus polyanthus Greenm. BASE, 6(2): 109-119.

Guéritaine G, Bonavent JF, Darmency H. 2003. Variation of prezygotic barriers in the interspecific hybridization between oilseed rape and wild radish. Euphytica, 130: 349-353.

Gupta VP, Plaha P, Rathore PK. 2002. Partly fertile interspecific hybrid between a black gram $\mathrm{x}$ green gram derivative and an adzuki bean. Plant Breeding, 121: 182-183.
Gurusamy V, Vandenberg A, Bett KE. 2007. Manipulation of in vivo pollination techniques to improve the fertilization efficiency of interspecies crosses in the genus Phaseolus. Plant Breeding, 126: 120-124.

Hillocks RJ, Madata CS, Chirwa R, Minja EM, Msolla S. 2006. Phaseolus bean improvement in Tanzania, 1959-2005. Euphytica, 150: 215-231.

Jansky S. 2006. Overcoming hybridization barriers in potato. Plant Breeding, 125: 112.

Jenczewski E, Ronfort J, Chèvre AM. 2003. Crop to wild gene flow, introgression and possible fitness effects of transgenes. Environmental Biosafety Research, 2: 924.

Kaufmane E, Rumpunen K. 2002. Pollination, pollen tube growth and fertilization in Chaenomeles japonica (Japanese quince). Scientia Horticulturae, 94(3-4): 257-271.

Kouadio D, Toussaint A, Pasquet R, Baudoin JP. 2006. Barrières pré-zygotiques chez les hybrides entre formes sauvages du niébé, Vigna unguiculata (L.) Walp. BASE, 10(1): 33-41.

Mahuku GS, Jara CE, Cajiao C, Beebe S. 2003. Sources of resistance to angular leaf spot (Phaeoisariopsis griseola) in common bean core collection, wild Phaseolus vulgaris and secondary gene pool. Euphytica, 130: 303-313.

Nguema NP, Toussaint A, Baudoin JP. 2009. Development of HY1 hybrid embryos between a cultivar of Phaseolus vulgaris $\mathrm{L}$ and a wild genotype of $P$. coccineus $\mathrm{L}$. Int. J. Biol. Chem. Sci., 3(1): 20-26.

Nguema NP, Toussaint A, Baudoin JP. 2013. Etude histologique des embryons avortés lors des croisements entre Phaseolus vulgaris L. et Phaseolus coccineus L. Int. J. Biol. Chem. Sci., 7(1): 213-224.

Nyabyenda P. 2005. Les Plantes Cultivées en Régions Tropicales d'Altitude d'Afrique : Généralités, Légumineuses Alimentaires, Plantes à Tubercules et Racines, Céréales. Presses Agronomiques de Gembloux: Gembloux. 
Nzungize RJ. 2012. Identification of Pythium species inducing common bean (Phaseolus vulgaris L.) root rot symptoms and development of backcrosses to improve the level of varietal resistance to this disease. Thèse de doctorat. Université de Liège Gembloux Agro-Bio Tech. Belgique, 119 p.

Nzungize J, Gepts P, Buruchara R, Male A, Ragama P, Busogoro P, Baudoin JP. 2011. Introgression of Pythium root rot resistance gene into Rwandan susceptible common bean cultivars. African Journal of Plant Science, 5(3): 193-200.

Silué S. 2009. Mécanismes génétiques de l'embryogenèse chez Phaseolus et application en hybridation interspécifique. Thèse de doctorat. Faculté universitaire des Sciences agronomiques. Gembloux, Belgique, 172 p.

Singh R, Sharma P, Varshney RK, Sharma SK, Singh NK. 2008. Chickpea Improvement: Role Of Wild Species And Genetic Markers. Biotechnology And Genetic Engineering Reviews, 25: 267314.

Tischner T, Allphin L, Chase K, Orf JH, Lark KG. 2003. Genetics of seed abortion and reproductive traits in soybean. Crop Science, 43: 464-473.
Tsiantis M, Hay A. 2003. Comparative plant development: the time of the leaf? Nature Reviews Genetics, 4: 169-180.

Umehara M, Ikeda M, Kamada H. 2007. Endogenous factors that regulate plant embryogenesis: Recent advances. Japanese Journal of Plant Science, 1: 16.

Wang Y, Scarthi R, Campbell C. 2002. Interspecific hybridization between Fagopyrum tataricum (L.) Gaertn. and F. esculentum Moench. Fagopyrum, 19: 3135.

Wolf PG, Campbell DR, Waser NM, Sipes SD, Toler TR, Archibald JK. 2001. Tests of pre- and postpollination barriers to hybridization between sympatric species of Ipomopsis (Polemoniaceae). Am. J. Bot., 88(2): 213-219.

Yamagishi H, Landgren M, Forsberg J, Glimelius K. 2002. Production of asymetric hybrids between Arabidopsis thaliana and Brassica napus utilizing an efficient protoplast culture system. Theoretical and Applied Genetics, 104(67): 959-954. 